\title{
К ВОПРОСУ О КРАТКОСРОЧНОМ ПРОГНОЗИРОВАНИИ МАССОВЫХ ПРОТЕСТНЫХ АКЦИЙ
}

\author{
Е.К. Басаева*, Е.С. Каменецкий ${ }^{* *}$, 3.Х. Хосаева ${ }^{* * *}$
}

Аннотация. Статья посвящена совершенствованию методов прогнозирования протестной активности. Выдвинута гипотеза о том, что рост социальной напряженности, оцениваемый по адекватным статистическим индикаторам, может служить предвестником массовых протестных акций. Для проверки выдвинутой гипотезы рассмотрены процессы, происходившие в странах Закавказья с 1996 г. до первой половины 2010-х га. В 71 \% спучаев роста напряженности в республиках Закавказья в течение следующих трех лет наблюдался всплеск протестной активности. В 37,5 \% случаях усилению протестной активности не предшествовал рост напряженности. Таким образом, предлагаемый метод может быть использован для прогнозирования всплесков протестной активности.

Ключевые слова: протестная активность, социальная напряженность, прогноз, Закавказье.

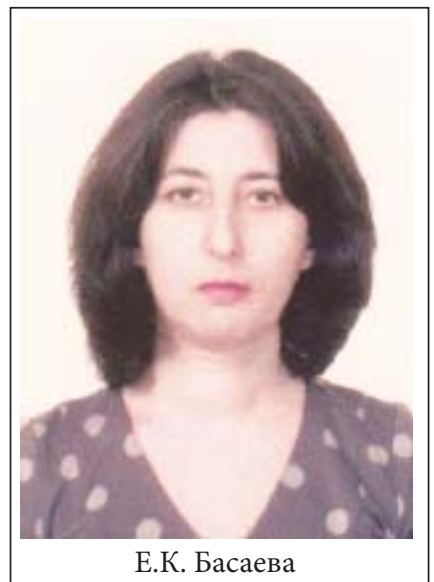

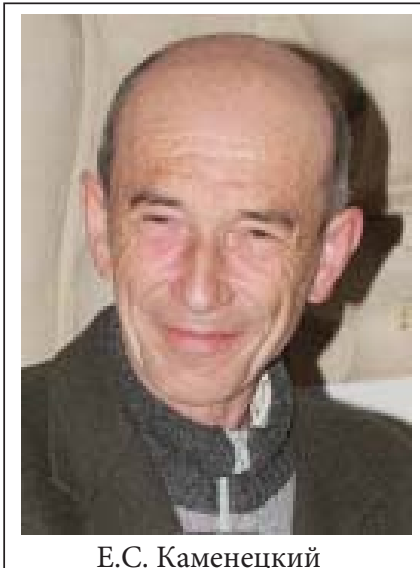

Е.С. Каменецкий

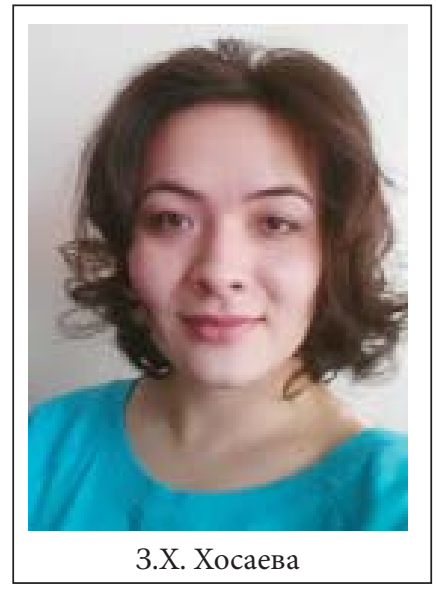

В настоящее время совершенствование методов прогнозирования нестабильности общества, в частности революций и гражданских войн, привлекает внимание многих исследователей [1-3]. Растущий интерес к этой проблематике связан с возникшей дестабилизацией во многих регионах мира, связанной с распадом социалистической системы и установлением однополярного мира. Часто дестабилизация начинается с усиления протестной активности населения, которая, особенно при наличии внешнего воздействия, может привести к смене власти или гражданской войне.

Возникновение массовых протестных акций зависит от социальной напряженности общества и наличия элитных групп, стремящихся усилить напряженность и использовать ее в своих целях. В связи с этим можно предположить, что рост напряженности может служить предвестником массовых протестных акций.

Непосредственное измерение социальной напряженности невозможно, поэтому будем оценивать ее по адекватным статистическим индикаторам. В качестве индикаторов можно использовать число убийств (или убийств и покушений на убийства), число самоубийств и число непредумышленных отравлений алкоголем (все перечисленные индикаторы берутся в пересчете на 100000 человек населения) [4, 5]. Выбор индикаторов в каждом конкретном случае зависит как от наличия достаточно длинных рядов соответствующих статистических данных, так и особен- ностей страны, для которой оценивается социальная напряженность.

Для проверки предположения о том, что рост напряженности может рассматриваться как предвестник роста протестной активности, рассмотрим процессы, происходившие в странах Закавказья с 1996 г. до первой половины 2010-х гг. В качестве индикатора социальной напряженности для этих стран используем число убийств на 100 тысяч человек населения. Этот индикатор является наиболее надежным, хотя и он подвержен преднамеренным и непреднамеренным искажениям. Поэтому для анализа используем данные четырех источников [6-9]. Рост напряженности будем считать существенным, если по всем имеющимся источникам данных число убийств увеличилось за год более чем на $10 \%$.

Азербайджан. Согласно таблице 1 значительный рост числа убийств в Азербайджане наблюдался только в 2010 г. Отметим, что в течение трех лет перед этим ВВП республики стабильно рос так, что всплеск напряженности нельзя объяснить ухудшением жизни населения. В 2011-2014 гг. отмечались протестные акции, со сравнительно незначительным числом участников, которые были разогнаны силами безопасности. «На митинги в марте - апреле 2011 г. в Баку вышли не более полутысячи человек, и властям не составило труда подавить эти протесты» [10]. В 2012 г. полиция разогнала митинг, в котором участвовало порядка 200 человек. В 2013 г. протестные акции прошли в Исма-

`Басаева Елена Казбековна - к. фр.-м. н., доцент, Южный математический институm ВНЦ РАН, вед. н. c., COГУ (helen@smash.ru).

- Каменецкий Евгений Самойлович - д. ф.-м. н., профессор, гл. н. с., Южный математический инстuтуm BHЦ PAH (esk@smath.ru).

“Хосаева Зарина Хетаговна - научный сотрудник КНИО, ВНЦ РАН (hzaiac83@mail.ru). 
Таблица 1

Статистические данные по Республике Азербайджан

\begin{tabular}{|r|r|r|r|r|r|r|}
\hline \multirow{2}{*}{ Год } & \multicolumn{2}{|c|}{ Убийства на 100000 населения } & \multicolumn{1}{l}{$\begin{array}{l}\text { Минимальное } \\
\text { изменение } \\
\text { числа убийств } \\
\text { за год, \% }\end{array}$} & $\begin{array}{l}\text { Темп роста } \\
\text { ВВП по ППС } \\
\text { на душу } \\
\text { населения [6] }\end{array}$ \\
\hline 1996 & & 5,15 & & 7,9 & & \\
\hline 1997 & & 3,6 & & 6,4 & $-30,10 \%$ & \\
\hline 1998 & & 4,3 & & 6 & $-6,25 \%$ & \\
\hline 1999 & & 3 & & 4,8 & $-30,23 \%$ & \\
\hline 2000 & 2,8 & 2,8 & 2,8 & 3,2 & $-33,33 \%$ & \\
\hline 2001 & 2,7 & 2,7 & 2,7 & 2,7 & $-15,63 \%$ & \\
\hline 2002 & 2,6 & 2,75 & 2,6 & 2,8 & $-3,70 \%$ & \\
\hline 2003 & 2,2 & 2,4 & 2,2 & 2,6 & $-15,38 \%$ & \\
\hline 2004 & 2,4 & 2,6 & 2,4 & 1,9 & $-26,92 \%$ & \\
\hline 2005 & 2,2 & 2,35 & 2,2 & & $-9,62 \%$ & \\
\hline 2006 & 2,2 & 2,3 & 2,2 & & $-2,13 \%$ & \\
\hline 2007 & 2 & 2,1 & 2 & 2,1 & $-9,09 \%$ & $27,12 \%$ \\
\hline 2008 & 1,9 & & 1,9 & 2,1 & $-5,00 \%$ & $11,30 \%$ \\
\hline 2009 & 1,8 & & 1,8 & & $-5,26 \%$ & $8,44 \%$ \\
\hline 2010 & 2,1 & & 2,1 & & $16,67 \%$ & $5,01 \%$ \\
\hline 2011 & 2,2 & & & & $4,76 \%$ & $-0,83 \%$ \\
\hline 2012 & 2,3 & & & & $4,55 \%$ & $2,59 \%$ \\
\hline 2013 & 2,5 & & & & $8,70 \%$ & $6,18 \%$ \\
\hline
\end{tabular}

илле и Баку. В марте 2014 г. в акции участвовало от 900 до 2500 человек. Однако и такие, сравнительно малочисленные, акции в условиях авторитарного режима в Азербайджане могут рассматриваться как заметный всплеск протестной активности.

Протестные акции, жестоко подавленные силами безопасности, имели место также после выборов Ильхама Алиева в 2003 г. [11], хотя перед 2003 г. число убийств в течение нескольких лет уменьшалось.

Грузия. В Грузии значительный рост напряженности наблюдался дважды - в 2001 и 2005 гг. (таблица 2). В обоих случаях в предыдущие годы имел место существенный рост ВВП. Через два года после первого увеличения напряженности произошла так называемая «революция роз»: протестные выступления, приведшие к отставке Э. Шеварднадзе. «В дни после состоявшихся 2 ноября 2003 года выборов на улицы вышло едва ли более 5 тысяч демонстрантов, позднее к протестам присоединилось дополнительно около 20 тысяч человек. Не мобилизующая сила оппозиции, а ее медийная поддержка со стороны телеканала «Рустави 2» оказалась решающей для перемены настроений в стране» [12]. Через два года после второго всплеска числа убийств в 2009 г. также имели место многолюдные демонстрации против переноса выборов. «В сентябре произошел пробный митинг, а в ноябре началась акция протеста. Судя по численности присутствовавших, она была самой масштабной за всю историю постсоветской Грузии. Однако, поскольку программы партий были разными и постоянно менялись по ходу митинга, а также в силу естественных причин, число митингующих быстро сокращалось, и 7 ноября акция была разогнана, а результатом ста- ло введение чрезвычайного положения и запрета на трансляцию оппозиционных каналов» [13].

Рост протестной активности наблюдался также после попытки вторжения Грузии в Южную Осетию в 2008 г. Согласно [13] «с апреля по сентябрь 2009 г. продолжались безрезультатные уличные акции». Протестные акции состоялись в Грузии и в мае 2011 г. В Тбилиси и Батуми в митингах, на которых выдвигалось требование отставки президента Грузии М. Саакашвили, участвовало более 10000 человек. Этим протестным акциям не предшествовал рост социальной напряженности. Их причиной, скорее всего, явилось поражение Грузии в войне в Южной Осетии.

Армения. В Армении заметное увеличение напряженности наблюдалось четыре раза - в 2004, 2006, 2011 и 2014 годах (см. таблицу 3). Первый случай был, возможно, следствием волны протестов 2003 и 2004 гг., связанных с выборами. В последующие три года, 20052007 гг., существенных протестных акций не было.

Примерно через год после роста напряженности в 2006 г. «1 марта 2008 г. в результате подавления массовых протестов властями погибли 10 человек, десятки были ранены» [14].

Третий рост напряженности, наблюдавшийся в 2011 г., был, скорее всего, связан с экономическим кризисом 2009 г. и не привел к росту протестной активности, поскольку наиболее энергичная часть населения предпочла политической борьбе эмиграцию. В [15] отмечается, что «наличие более-менее благополучной диаспоры во многих частях света стимулирует поиск недовольными слоями общества выхода из тяжелого положения не в революции, а в отъезде за рубеж».

И, наконец, последний рост напряженности в 
Таблица 2

Статистические данные по Республике Грузия

\begin{tabular}{|c|c|c|c|c|c|c|}
\hline \multirow[t]{2}{*}{ Год } & \multicolumn{4}{|c|}{ Убийства на 100000 населения } & \multirow{2}{*}{$\begin{array}{l}\text { Минимальное } \\
\text { изменение } \\
\text { чнсла убийств } \\
\text { за год, \% }\end{array}$} & \multirow{2}{*}{$\begin{array}{l}\text { Темп роста } \\
\text { ВВП по ППС } \\
\text { на душу } \\
\text { населения } 6\end{array}$} \\
\hline & [6] & [7] & [8] & {$[9]$} & & \\
\hline 1996 & & 5 & & 5,4 & & \\
\hline 1997 & & 5,4 & & 5,8 & $7,41 \%$ & \\
\hline 1998 & & 4,6 & & 5 & $-14,81 \%$ & $5,20 \%$ \\
\hline 1999 & & 5,1 & & 5,1 & $2,00 \%$ & $5,37 \%$ \\
\hline 2000 & 5 & 5 & 5 & 5 & $-1,96 \%$ & $5,59 \%$ \\
\hline 2001 & 5,6 & 6 & 5,6 & 5,6 & $12,00 \%$ & $7,95 \%$ \\
\hline 2002 & 6,3 & 5,25 & 6,3 & 5,3 & $-12,50 \%$ & $7,90 \%$ \\
\hline 2003 & 6,6 & 6,8 & 6,6 & 6,6 & $4,76 \%$ & $14,82 \%$ \\
\hline 2004 & 6,6 & 4,9 & 6,6 & 6,2 & $-27,94 \%$ & $10,05 \%$ \\
\hline 2005 & 9 & 9,1 & 9 & 9 & $36,36 \%$ & $14,56 \%$ \\
\hline 2006 & 8,6 & 7,3 & 7,3 & 7,3 & $-18,89 \%$ & \\
\hline 2007 & 6,6 & 7,5 & 6,5 & 7,5 & $-23,26 \%$ & \\
\hline 2008 & 6,5 & & 6 & 6 & $-21,67 \%$ & \\
\hline 2009 & 4,9 & & 4,8 & 4,7 & $-24,62 \%$ & $-1,62 \%$ \\
\hline 2010 & 4,4 & & 4,3 & 4,1 & $-12,77 \%$ & \\
\hline 2011 & 2,7 & & & & $-38,64 \%$ & \\
\hline
\end{tabular}

Таблица 3

Статистические данные по Республике Армения

\begin{tabular}{|c|c|c|c|c|c|c|}
\hline \multirow[t]{2}{*}{ год } & \multicolumn{4}{|c|}{ Убийства на 100000 населения } & \multirow{2}{*}{$\begin{array}{l}\text { Минимальное } \\
\text { изменение } \\
\text { числа } \\
\text { убийств за } \\
\text { год, \% }\end{array}$} & \multirow{2}{*}{$\begin{array}{l}\text { Темп роста } \\
\text { ВВП по ППС } \\
\text { на душу } \\
\text { населения [6] }\end{array}$} \\
\hline & {$[6]$} & [7] & [8] & [9] & & \\
\hline 1996 & & 3 & & 3,6 & & \\
\hline 1997 & & 2,6 & & 3,15 & $-13,33 \%$ & \\
\hline 1998 & & 4,2 & & 3,15 & $0,00 \%$ & \\
\hline 1999 & & 4,5 & & 3,1 & $-1,59 \%$ & \\
\hline 2000 & & 3,2 & & 2,75 & $-28,88 \%$ & \\
\hline 2001 & & 2,3 & & 2,65 & $-28,13 \%$ & $12,71 \%$ \\
\hline 2002 & & 3,5 & & 2,25 & $-15,09 \%$ & $16,94 \%$ \\
\hline 2003 & & 2,2 & & 2,05 & $-37,14 \%$ & $16,72 \%$ \\
\hline 2004 & 2,7 & 2,9 & 2,7 & 2,4 & $17,07 \%$ & $13,86 \%$ \\
\hline 2005 & 1,9 & 1,8 & 1,9 & 1,8 & $-37,93 \%$ & $18,58 \%$ \\
\hline 2006 & 2,6 & 2,2 & 2,6 & 2,15 & $19,44 \%$ & $17,07 \%$ \\
\hline 2007 & 2,6 & 2,25 & 2,6 & 2,3 & $0,00 \%$ & $17,17 \%$ \\
\hline 2008 & 3,3 & 2,5 & 2,8 & 2,15 & $-6,52 \%$ & $9,41 \%$ \\
\hline 2009 & 3,3 & & 2,8 & 2,2 & $0,00 \%$ & $-13,21 \%$ \\
\hline 2010 & 1,9 & & 1,5 & & $-46,43 \%$ & $3,58 \%$ \\
\hline 2011 & 2,4 & & 2,2 & & $46,67 \%$ & $6,80 \%$ \\
\hline 2012 & 2,2 & & 1,8 & & $-18,18 \%$ & $9,03 \%$ \\
\hline 2013 & 2 & & & & $-9,09 \%$ & $4,62 \%$ \\
\hline 2014 & 2,4 & & & & $20,00 \%$ & $5,28 \%$ \\
\hline 2015 & 2,5 & & & & $4,17 \%$ & \\
\hline
\end{tabular}

2014 г. привел к усиливавшимся в течение последующих трех лет протестам, которые закончились сменой власти («бархатной революцией»).

Таким образом, в пяти из семи случаев роста напряженности в республиках Закавказья в течение следующих трех лет наблюдался всплеск протестной активности. В трех случаях усилению протестной активности не предшествовал рост напряженности: дважды причиной явилась неудовлетворенность результатами выборов, а в третьем - проигранная война.
Отметим также, что всплески протестной активности достаточно редко приводят к досрочной смене правящей группы. В странах Закавказья за рассматриваемый период из восьми всплесков протестной активности только в двух случаях имела место смена режима.

Как и в [3], одним из критериев оценки правильности предсказаний можно считать отношение числа случаев, для которых было правильно предсказано увеличение протестной активности, к общему числу случаев суще- 
ственного (более 10 \%) роста напряженности. Другим критерием является отношение числа случаев, когда росту протестной активности не предшествовал рост напряженности, к общему числу случаев роста протестной активности. Чем ближе это отношение к нулю, тем значимей влияние роста напряженности на протестную активность.

Для рассмотренного периода времени в трех стра- нах Закавказья значение первого критерия равно 0,71, а второго - 0,375. Это позволяет предположить, что предлагаемый метод может быть использован для прогнозирования всплесков протестной активности. Необходима его дальнейшая проверка как на данных по большему числу стран, так и на более длинных временных рядах для отдельной страны.

\title{
ЛИТЕРАТУРА
}

1. Goldstone J.A., Bates R.H., Epstein D.L., Gurr T.R., Lustik M.B., Marshall M.G., Ufelder J., Woodward M. A Global model for forecasting political instability // American Journal of Political Science - 2010. Vol 54, No. 1.P. 190-208.

2. Beger A., Dorff C.L., Ward M.D. Irregular leadership changes in 2014 Forecastsusung ensemble split-population duration models // International Journal of Forecasting. 2016. Vol. 32. Issue 1. P. 98-111. DOI: 10.1016/s. ijforecast.2015.01.009.

3. Mueller H., Rauh C. Reading between the lines: Prediction of political violence using newspaper text // American Political Science Review. 2018. Vol. 112. Issue 2. P. 358-375. DOI: 10.1017/S0003055417000570.

4. Басаева Е.К., Каменецкий Е.С., Хосаева З.Х. Количественная оценка фоновой социальной напряженности // Информационные войны. 2015, № 2. С. 25-28.

5. Басаева Е.К., Каменецкий Е.С., Хосаева 3.Х. Статистические индикаторы социальной напряженности // В сб.: Межнациональное согласие - социальный приоритет государственности. Материапы Междун. научно-практич. конф. - Владикавказ: Сев. Осет. гос. ун-т им. К.Л. Хетагурова, 2018. С. 236-244.

6. Мировой атлас данных. [UPL: https://knoema.ru/atlas] Дата обращения: 19.07.20182.

7. Petrini B. Homicide Rate Dataset 1995-2008. 2010. 39 pp.

[URL:http://siteresources.worldbank.org/EXTCPR/ Resources/407739-1267651559887/Homicide_Rate_Dataset.pdf] Дama обращения: 19.07.20182.
8. Intentional homicide count rate per 100,000 population, by country (2000-2012). [URL:www.unodc.org/documents/gsh/data/GSH2013 Homicide count and rate.xIsx] Дата обращения: 19.07.2018z.

9. 2011 Globalstudyon homicide: trends, contexts, data_-Vienna:United Nations Office on Drugs and Crime, 2011.128 p. URL: http://www.unodc. org/documents/data-and-analysis/statistics/Homicide/Globa_study_on_ homicide_2011_web.pdf Дата обращения: 19.07.20182.

10. Аббасов Ш. Азербайджан: достижения и упущенные возможности // В сб.: Южный Кавказ - 20 лет независимости. - Фонд Фридриха Эберта, 2011. С. 118-133. ISBN 978-9941-0-3793-8.

11. Юнусов А. Независимый Азербайджан двадцать лет спустя // Всб. Южный Кавказ - 20 лет независимости - Фонд Фридриха Эберта, 2011. С. 66-82. ISBN 978-9941-0-3793-8.

12. Йобелиус М. Авторитарный либерализм Грузии // В сб.: Южный Кавказ - 20 лет независимости. - Фонд Фридриха Эберта. С. 84100. ISBN 978-9941-0-3793-8.

13. Микаэлян Г. Внутренняя политика современной Грузии // 21-й BEK. 2010, №2 (14). C. 57-69.

14. Золян М. «Бархатная революция» в Армении: Достижения и неудачи // В сб.: Южный Кавказ - 20 лет независимости. - Фонд Фридриха Эберта, 2011. C. 45-65. ISBN 978-9941-0-3793-8.

15. Навасардян Б. Управление и политика в Армении: перспективы демократизации // В сб.: Южный Кавказ - 20 лет независимости Фонд Фридриха Эберта, 2011. С. 101-117.ISBN 978-9941-0-3793-8.

\section{TO THE ISSUE OF SHORT-TERM FORECASTING OF MASS PROTEST ACTIONS E.K. Basaeva ${ }^{1,2}$, E.S. Kamenetsky ${ }^{1}$, Z.Kh. Khosaeva ${ }^{1}$}

\author{
1 Vladikavkaz Scientific Center, Russian Academy of Sciences \\ ${ }^{2}$ North Ossetian State University named after K.L. Khetagurov. Vladikavkaz. Russia. \\ (esk@smath.ru)
}

\begin{abstract}
The article is devoted to the improvement of predicting protest activity methods. A hypothesis has been put forward that the growth of social tension, estimated by certain statistical indicators, can refer to emerging mass protest actions. In order to test the hypothesis, certain processes that took place in the countries of the Transcaucasus from 1996 to the first half of the 2010 are considered. In $71 \%$ cases of increased tension in the Transcaucasian republics, in the next three years surge of protest activity is expected. In $37.5 \%$ cases, the increase in protest activity has not been preceded by the increase in tension. Thus, the proposed method can be used to predict outbursts of protest activity.
\end{abstract}

Keywords: protest activity, social tensions, forecast, Transcaucasia.

\section{REFERENCES}

1. Goldstone J.A. Bates R.H. Epstein D. Gurr TR Lustik M.B. Marshall M.G.. Ufelder J.. Woodward M. A Global model for forecasting political instability // American Journal of Political Science. - 2010. Vol. 54. No. 1.P. $190-208$.

2. Beger A . Dorff C. L. Ward M.D. Irregular leadership changes in 2014: Forecastsusung ensemble split-population duration models // International Journal of Forecasting. 2016. Vol. 32. Issue 1. P. 98-111. DOI: 10.1016/j. ijforecast.2015.01.009.

3. Mueller H.. Rauh C. Reading between the lines: Prediction of political violence using newspaper text // American Political Science Review. 2018. Vol. 112. Issue 2. P. 358-375. DOI: 10.1017/S0003055417000570.

4. Basaeva E.K.. Kameneckij E.S.. Hosaeva Z.H. Kolichestvennaya ocenka fonovoj social'noj napryazhennosti // Informacionnye vojny. 2015. № 2. S. 25-28.

5. Basaeva E.K.. Kameneckij E.S.. Hosaeva Z.H. Statisticheskie indikatory social'noj napryazhennosti // V sb.: Mezhnacional'noe soglasie - social'nyj prioritet gosudarstvennosti. Materialy Mezhdun. nauchno-praktich. konf. Vladikavkaz: Sev. Oset. gos. un-t im. K.L. Hetagurova. 2018. S. 236-244. 6. Mirovoj atlas dannyh. [UPL: https://knoema.ru/atlas] Data obrashcheniya: 19.07.2018g.

7. Petrini B. Homicide Rate Dataset 1995-2008.

2010. 39 pp. [URL:http://siteresources.worldbank. org/EXTCPR/ Resources/407739-1267651559887/Homicide_Rate_Dataset.pdf]

Data obrashcheniya: 19.07.2018g.
8. Intentional homicide count rate per 100.000 population. by country (2000-2012). [URL:www.unodc.org/documents/gsh/data/GSH2013 Homicide_count_and_rate.xlsx] Data obrashcheniya: 19.07.2018g. 9. 2011 Globalstudyon homicide: trends. contexts. data.-Vienna:United Nations Office on Drugs and Crime. 2011.128 p. URL: http://www.unodc. org/documents/data-and-analysis/statistics/Homicide/Globa study on homicide_2011_web.pdf Data obrashcheniya: 19.07.2018g.

10. Abbasov SH. Azerbajdzhan: dostizheniya $i$ upushchennye vozmozhnosti // V sb.: YUzhnyj Kavkaz - 20 let nezavisimosti. - Fond Fridriha EHberta. 2011. S. 118-133. ISBN 978-9941-0-3793-8.

11. YUnusov A. Nezavisimyj Azerbajdzhan dvadcat' let spustya // Vcb. YUzhnyj Kavkaz - 20 let nezavisimosti. - Fond Fridriha EHberta. 2011. S. 66-82. ISBN 978-9941-0-3793-8.

12. Jobelius M. Avtoritarnyj liberalizm Gruzii // V sb.: YUzhnyj Kavkaz - 20 let nezavisimosti. - Fond Fridriha EHberta. S. 84-100. ISBN 978-9941. 0-3793-8.

13. Mikaehlyan G. Vnutrennyaya politika sovremennoj Gruzii // 21-j VEK. 2010. №2 (14). S. 57-69.

14. Zolyan M. "Barhatnaya revolyuciya» v Armenii: Dostizheniya neudachi // V sb.: YUzhnyj Kavkaz - 20 let nezavisimosti. - Fond Fridriha EHberta. 2011. S. 45-65. ISBN 978-9941-0-3793-8.

15. Navasardyan B. Upravlenie i politika $v$ Armenii: perspektivy demokratizacii // V sb: YUzhnyj Kavkaz - 20 let nezavisimosti. - Fond Fridriha EHberta. 2011. S. 101-117.ISBN 978-9941-0-3793-8.

\section{BEСТНИК

